\title{
Representaciones escolares del saber geográfico
}

\author{
Xosé M. Souto González \\ Diego García Monteagudo \\ Universitat de València
}

\section{Resumen}

En los años sesenta-setenta del siglo XX se produjo un debate relevante sobre la comprensión de los hechos y fenómenos sociales. Desde la Geografía y otras ciencias sociales se buscó la explicación del comportamiento humano en relación con el recuerdo del pasado, las relaciones sociales, la valoración espacial o la representación social del sistema escolar. Nuestro objetivo es mostrar los obstáculos que aparecen en el medio académico como referente para la construcción de un espacio público educativo, donde la Geografía pueda manifestar sus competencias para facilitar un aprendizaje útil al conocimiento del medio local en su contexto global.

Palabras clave: Geografía. Representaciones sociales del sistema escolar. competencias.

\section{Representações escolares de conhecimento geográfico}

\section{Resumo}

Nos anos sessenta-setenta do século XX produziu-se um debate relevante sobre a compreensão de como se produzem os fatos e fenômenos sociais. Tanto na Geografia como em outras ciências sociais buscou-se a explicação do comportamento humano relacionando-o com a memória do passado, as relações sociais, a valoração espacial ou a representação social do sistema escolar. $\bigcirc$ objetivo deste artigo consiste em refletir sobre os obstáculos que atuam no meio acadêmico como referentes para a construção de um espaço público educativo, onde a Geografia possa manifestar as suas competências para facilitar uma aprendizagem útil ao conhecimento do meio local no contexto global.

Palavras-chave: Geografia. Representações sociais do sistema escolar. Competências.

\section{School representations of geographical knowledge}

\begin{abstract}
In the sixties and seventies of the twentieth century there was an important discussion on the explanation of the facts and social phenomena. Since geography and other social sciences the explanation of human behaviour in relation to the memory of the past, social relations, spatial
\end{abstract}


Representaciones escolares del saber geográfico

assessment or social representation of the school system was sought. Our aim is to show the obstacles that appear in academic means as a reference for the construction of an educational public space where geography can manifest their powers to facilitate useful learning the knowledge of the local environment in its global context.

Keywords: Geography. Social representations of school system. Powers.

\section{Introducción}

El trabajo docente en el sistema escolar es complejo por la diversidad de tareas y las emociones que se generan en los ámbitos del aula y centro. Los profesores y profesoras son personas que quieren persuadir a sus alumnos acerca de la explicación de los fenómenos físicos y sociales que organizan el mundo. Pero existe una resistencia que va más allá de la comprensión conceptual o el dominio de las habilidades cognoscitivas. Es una actitud, más de una vez pre-reflexiva, que se enfrenta a la racionalidad científica. Existe en las personas, que conocemos como alumnos, un hábito de comprensión vulgar del mundo que genera explicaciones "ad hoc". Y en esta manera de comprender y explicar el mundo se impone la naturalización de ciertos hechos sociales. Una

12 manera de reflexionar que genera un comportamiento ciudadano.

Coincidimos con Horacio Capel, quien indicaba que en los años setenta del siglo XX se estaba asistiendo a un cambio importante en la explicación de los hechos y acontecimientos sociales, que él denominaba el giro del comportamiento (CAPEL, 1973). Frente a la lógica positivista de los modelos cuantitativos aparecía la interpretación fenomenológica de los hechos humanos; una forma de explicar que se tipificó como Geografía Humanística y como Geografía de la Percepción y del Comportamiento (BOIRA; REQUES, 19911. Se consideraban las emociones, las intenciones y los comportamientos humanos, tal como sucedía en otras ciencias sociales. En los primeros decenios del siglo XXI los avances en las investigaciones de la neurociencia (DÍAZ, 2007; DAMASIO, 2010) avalaron desde evidencias empíricas la influencia de las emociones y sentimientos en los razonamientos y decisiones individuales y colectivas.

Todas estas consideraciones teóricas nos muestran que las propuestas de aprendizaje en la sociedad de la información, luego de la revolución tecnológica de Internet, tiene que ser diferente a la de hace un siglo. Pero las 
rutinas escolares nos retrotraen muchas veces al siglo XIX. ¿̨Por qué es tan difícil innovar en la enseñanza de la Geografía y las ciencias sociales?

En este artículo queremos mostrar las posibilidades de un diálogo interdisciplinar entre la sociología de las representaciones sociales, y la obra de Serge Moscovici, en relación con el análisis de las imágenes mentales del espacio geográfico, que en el medio escolar se construye en las diferentes escalas que explican el mundo, desde el medio local a la estructura global.

En primer lugar nos acercamos al modelo teórico que asumimos como referente en nuestra investigación. Más tarde avanzamos una propuesta metodológica que nos ha permitido trabajar con las ideas de futuros profesores, maestras y docentes en ejercicio y alumnos de Educación Secundaria. Con ellas hemos querido interpretar las concepciones espontáneas que expresan las personas y cómo ello incide en su comportamiento escolar y ciudadano, en tanto que las aulas y los centros funcionan en diferentes momentos como "nichos ecológicos" del sistema social.

\section{Las representaciones sociales y la geografía de la percepción: el paradigma de la comprensión del comportamiento}

Como señalamos, el comportamiento docente es difícil de analizar, pues depende no sólo de análisis y conocimiento de la realidad escolar y de los hechos propios de la materia, sino también de las decisiones del profesorado. Por este motivo nos hemos interesado por la sociología de la educación, no sólo para conocer el contexto social del centro escolar, sino también para entender las representaciones sociales que determinan una manera $u$ otra de educar en los problemas sociales desde Geografía.

En otro momento ya hemos insistido en que las diferentes tendencias filosóficas nos permiten explicar el contexto escolar y ciudadano donde se produce el aprendizaje (SOUTO, 2010). Por eso mismo hemos extraído algunas ideas sobre las implicaciones de este tipo de conocimientos en el momento de la programación docente. Las experiencias de otros grupos de innovación de España (por ejemplo los de Fedicaria) y de lberoamérica (los que se reúnen en Redladgeo y en el Geoforo|2, han puesto de manifiesto la necesidad de definir un marco teórico en el cual se contextualiza la innovación. 
Desde una posición epistémica, la apuesta por el constructivismo no es sólo un enfoque desde la psicología cognitivista, sino también una confluencia con el mundo de la Geografía de la percepción y de las representaciones sociales. Existe, pues, una continua reformulación de los objetivos y metodologías del análisis de la realidad social desde las distintas ciencias sociales y ello nos permite establecer el diálogo interdisciplinar ${ }^{3}$.

¿Por qué planteamos esta confluencia de enfoques? En primer lugar, porque desarrollamos una vía de argumentación que se remonta a los años ochenta del siglo pasado, donde buscábamos vías de renovación pedagógica para superar nuestro desagrado con los modos tradicionales de enseñanza de la Geografía y que la sentíamos en nuestros aprendizajes de la enseñanza básica y universitaria. En segundo lugar, porque observamos que dicha búsqueda particular estaba sustentada en un giro filosófico en las ciencias sociales que se denominaba del comportamiento (CAPEL, 1973). Más adelante, pudimos comprobar que este enfoque filosófico estaba presente en las formulaciones de un constructivismo social que se apoyaba en las teorías de Vygotski para explicar la construcción del conocimiento social. Luego llegarían las evidencias empíricas de la neurociencia.

$14 \quad$ Al mismo tiempo, desde las ciencias de la educación se buscaba un modelo teórico que facilitara el análisis de las concepciones del docente en la comunicación de aula. En el caso concreto de la enseñanza de la Geografía disponemos del trabajo de doctorado de Josélia Saraiva (2007) que sigue los presupuestos teóricos de Domingos Sobrinho (2000), quien encuentra en la síntesis entre P. Bourdieu y S. Moscovici un modelo interpretativo de las concepciones espontáneas del docente, que tanto influyen en el momento de la práctica escolar. Una línea de trabajo que nos parece acertada, pues continúa el trabajo realizado desde la Geografía de la Percepción y del Comportamiento.

La Geografía de la Percepción nos puso de relieve que la Geografía no era sólo lo que se veía con los ojos (el paisaje, la morfología urbana), sino que también consistía en la representación mental del territorio percibido con los filtros de las emociones y de los prejuicios culturales. Si desde el constructivismo se hacía mención a la importancia de las concepciones previas, para poder edificar un conocimiento socialmente útil, era evidente que el análisis de dichas representaciones era básico para entender el comportamiento docente y discente. 
Sin embargo, las teorías epistémicas de las escuelas de Geografía no son conocidas por el alumnado de los Máster de Geografía y tampoco en el profesorado que acude voluntariamente a los cursos y seminarios de formación continua. En estudios anteriores hemos mostrado diferentes estadísticas que confirmaban este fenómeno (SOUTO; GARCÍA MONTEAGUDO, 2016). Hemos observado que tanto en el profesorado en activo, como en los futuros profesores de Educación Secundaria, el conocimiento de las nuevas Geografías es escaso. Pero este desconocimiento contrasta con las competencias que se presuponen a un futuro docente, que debe saber seleccionar los problemas sociales y ambientales ${ }^{4}$.

La selección de las 241 personas que han sido analizadas obedecen a un doble criterio: la oportunidad de trabajar con ellos/ellas en cursos de formación y, en segundo lugar, la posibilidad de penetrar en sus concepciones con el estudio de sus movimientos corporales, entonaciones, debates que se produjeron en los grupos de discusión. Para ello hemos utilizado la oportunidad de trabajar con personas que aceptaron desarrollar los debates de forma voluntaria (Cali, Porto Alegre y profesores en ejercicio en Valencia), mientras que otros lo hacían dentro de un curso de Grado o Máster (Universidad de Valencia), lo que generaba que su posición personal estaba delimitada por su rol de alumno.

El dilema consiste en explicar cómo se puede efectuar dicha selección que conecte con los pensamientos y emociones del alumnado si no se conoce el marco teórico de la Geografía de la Percepción o la Humanística; en efecto, cuando hemos analizado las respuestas de dichos 241 alumnos de Grado de Maestro en Enseñanza Primaria y del Máster en Educación Secundaria, hemos podido apreciar que la valoración superior se correspondía con la selección de dichos problemas sociales y ambientales.

Tras el dilema anterior surge una paradoja que a nuestro modo de ver se corresponde con un doble estereotipo. Por una parte pedagógico, pues se entiende que la práctica de las aulas no precisa de una reflexión teórica para organizar la secuencia de actividades. Por otra parte académico, como es la falta de vinculación de la enseñanza de la Geografía con las investigaciones universitarias. Así cuando pedimos a los futuros docentes que nos definan las características de un profesor de Geografía o de ciencias sociales, hemos observado que las palabras que más se repiten corresponden a dinamismo, motivación, curiosidad o persona informada (Tabla 1). Sólo aparecen 
referencias más explícitas al saber de los problemas sociales en el caso de los profesores en activo; bien sea desde una perspectiva más crítica en el caso de Porto Alegre (Brasil), más creativa y didáctica en el caso de Cali (Colombia) o en el carácter enciclopédico e interdisciplinario del docente de Geografía, en el caso de Valencia.

Para avanzar en las imágenes y percepciones que van condicionando la construcción de las representaciones sociales del profesorado, hemos buscado, a través de la asociación libre de palabras, cuáles definen mejor la concepción de profesor de geografía e incluso de esta materia como tal, para lo que se consideraba la frecuencia y el orden de las mismas 5 . Así solicitamos del alumnado que escribiera las tres/cinco palabras que mejor definían sus conceptos de profesor de geografía y la propia materia (ver tablas 1 y 2).

Las palabras seleccionadas obedecen a una percepción del saber escolar que es producto tanto de su formación académica como de su cosmovisión como docentes o futuros profesores. El espacio vivido, emocional, influye en esta asociación de palabras, pero también el espacio relacional, que es consecuencia de la valoración del saber geográfico por parte de amigos, familiares, medios de comunicación, políticos, otros docentes. Por eso enten16 demos que es coherente establecer la relación entre este espacio relacional o complejo y el mundo de las representaciones sociales, pues desde el marco social se condicionan las ideas del medio escolar.

De esta manera aspirábamos a delimitar el núcleo central de las representaciones del alumnado, siguiendo las orientaciones de Abric (2000). Sabemos que dicho núcleo central se diferencia del periférico (MOLINER; ABRIC, 2015) por su estabilidad y escaso número de elementos que lo definen. Además como subrayan los mismos autores, Moliner y Abric (2015), es difícil de definir sólo por la asociación libre de palabras o por la jerarquización de las mismas; parece preciso saber qué elementos se excluyen de dicho núcleo central, para lo que se precisa un análisis de refutación o corroboración de ciertas ideas. Por todo ello, lo que presentamos en esta tabla 1 es una selección de palabras que para las personas encuestadas se relacionaban con su percepción de profesor/a de geografía en el sistema escolar. 


\section{Tabla 1}

\section{Palabras Asociadas a Profesor/a de Geografía}

\begin{tabular}{|c|c|c|}
\hline Grupos personas & Palabas asociadas & Comentario \\
\hline $\begin{array}{l}24 \text { personas de Porto Alegre. } \\
\text { Brasil. (Mestrado, Máster: mayo- } \\
\text { ría de profesorado en ejercicio) } \\
31 / 08 / 2015\end{array}$ & $\begin{array}{l}\text { Política, criticidade conhecimen- } \\
\text { to, criatividade, diálogo, saber, } \\
\text { comunicação, didática, apren- } \\
\text { dizagem, paixão, sensibilidade, } \\
\text { compromisso, inovação, dedica- } \\
\text { ção, atualização, responsável, } \\
\text { utópico, reflexivo. }\end{array}$ & $\begin{array}{l}\text { Fue un curso de Mestrado y los } \\
\text { profesores estaban comprome- } \\
\text { tidos políticamente. Formación } \\
\text { continua }\end{array}$ \\
\hline $\begin{array}{l}15 \text { personas de Olimpíadas } \\
\text { de Geografía UV (docentes en } \\
\text { ejercicio) } \\
4 / 3 / 2016\end{array}$ & $\begin{array}{l}\text { Interdisciplinares (8), Motivación } \\
\text { (3) Actualidad (3) Dinamismo( 2) } \\
\text { Paciencia (2) Saber enciclopédi- } \\
\text { co (2). }\end{array}$ & $\begin{array}{l}\text { Fue un encuentro con profe- } \\
\text { sores que colaboraban con } \\
\text { la Universidad de Valencia } \\
\text { Formación continua }\end{array}$ \\
\hline $\begin{array}{l}29 \text { personas de Cali. Colombia. } \\
\text { (alumnos Mestrado y docentes en } \\
\text { ejercicio) } \\
8 / 10 / 15\end{array}$ & $\begin{array}{l}\text { Dinámico }(5) \text {, Propositivo (3), } \\
\text { Creativo }(5) \text {, Reflexivo }(6) \text {, didácti- } \\
\text { co }(4) \text {, coherencia }(4) \text {, autónomo, } \\
\text { conceptos, investigador... }\end{array}$ & $\begin{array}{l}\text { Seminario con ocasión del } \\
\text { Encuentro Nacional de } \\
\text { Geografía Formación continua }\end{array}$ \\
\hline $\begin{array}{l}30 \text { personas del Máster } \\
\text { de Secundaria UValencia } \\
\text { (Alumnado, futuros docentes) } \\
22 / 10 / 2015\end{array}$ & $\begin{array}{l}\text { Activa y dinámica }=3 ; \text { Es una per- } \\
\text { sona informada }=2 \text {. Una persona } \\
\text { con retórica }=1 ; \text { Con cultura }=1\end{array}$ & $\begin{array}{l}\text { Resultados del trabajo en equi- } \\
\text { po comparando las diferentes } \\
\text { percepciones individuales. } \\
\text { Formación inicial }\end{array}$ \\
\hline $\begin{array}{l}35 \text { personas de } 3^{\circ} \text { Grado } \\
\text { (Alumnado, futuros docentes), } \\
29 / 10 / 2015 \\
\text { (Futuros docentes, alumnos de } \\
\text { Grado de Universidad Valencia) }\end{array}$ & $\begin{array}{l}\text { historiador (5); conocimiento } \\
(4) \text {; aburrido (4), comunicador } \\
(4) \text {; leer libro } 3 \text {; memorizar (3). } \\
\text { Adoctrinador y exámenes (2) } \\
\text { cada uno. }\end{array}$ & $\begin{array}{l}\text { Las palabras corresponden a } \\
\text { profesor de ciencias sociales. } \\
\text { Formación inicial }\end{array}$ \\
\hline $\begin{array}{l}30 \text { personas, } 4^{\circ} \text { Grado de } \\
\text { Magisterio (Alumnado, futuros } \\
\text { docentes de la UV) } \\
14 / 09 / 2015\end{array}$ & $\begin{array}{l}\text { Dinamismo: } 18 \text { personas; } \\
\text { Motivación: } 11 \text {; } \\
\text { Otras repetidas: curiosidad, } \\
\text { igualdad, experimentación, ac- } \\
\text { tualizado, innovador, creatividad }\end{array}$ & $\begin{array}{l}\text { Grupo de debate sobre el sig- } \\
\text { nificado del dinamismo y la } \\
\text { práctica docente. Formación } \\
\text { inicial }\end{array}$ \\
\hline $\begin{array}{l}40 \text { personas. Máster de } \\
\text { Formación de Profesorado de } \\
\text { Secundaria (Alumnado, futuros } \\
\text { docentes) } \\
25 / 10 / 2016 .\end{array}$ & $\begin{array}{l}\text { Práctico-metódico (16) } \\
\text { Organizado-actividades (10), } \\
\text { Pasmo-aburrido (10) Dinámico } \\
\text { (9), Carismático (7) Teoría-Espeso } \\
\text { (6), Tradicional, monótono, } \\
\text { actualizado-informado, crítico, } \\
\text { respetuoso, empático (4). }\end{array}$ & $\begin{array}{l}\text { Se han diferenciado las } \\
\text { palabras positivas (verde) y ne- } \\
\text { gativas (rojo). Dicotomía: teoría } \\
\text { vs. práctica, que se completa- } \\
\text { ba con dinamismo vs. Aburrido. } \\
\text { Formación inicial }\end{array}$ \\
\hline
\end{tabular}

Fuente: Encuestas, cuestionarios y grupos de debate. Elaboración propia 
Parece que podemos avanzar la hipótesis que indica que las representaciones del docente de Geografía están relacionadas con una visión desde el sentido común (sus representaciones sociales) y que es aceptada como tal por el futuro profesorado. Así estudiar ciencias sociales, geografía o historia, se corresponde sobre todo con una imagen del aprendizaje memorístico de hechos y conceptos que se han sintetizado desde el conocimiento académico y que forma parte de lo que se denomina la cultura distinguida. Es decir, existe una cesura entre lo que se expone en el conocimiento académico y lo que se transmite como profesión o difusión de este conocimiento específico, que se entiende como la aplicación o instrucción de dicho saber. Menos común era la imagen del docente de la enseñanza básica en contacto con los centros universitarios para poder estudiar o reflexionar sobre cómo se produce el aprendizaje humano sobre los hechos sociales, como en este caso sobre el espacio geográfico; una afirmación que ya había sido realizada en el curso de investigaciones anteriores sobre la enseñanza de la geografía (RAMIRO, 1998).

En este último aspecto disponemos de la evidencia de cómo se ha difundido la Geografía de la Percepción en España y cómo aparece en otros países. Así en el caso portugués disponemos de un trabajo publicado en la 18 revista del Centro de Estudos Geográficos en la sección de enseñanza, en la cual se exponen las líneas básicas de la percepción del espacio geográfico (GASPAR; MARÍN, 1975), con ejemplos de aplicación didáctica con alumnos de diferentes niveles escolares, si bien su difusión a través de la revista universitaria Finisterra era poco relevante.

En España, pese a la rápida sistematización de esta escuela geográfica (CAPEL, 1973; ESTÉBANEZ, 1979) no se avanzó lo suficiente en la aplicación didáctica hasta los años ochenta, en especial por medio de la difusión que se hace de esta escuela por Pedro Reques y Josep V. Boira (1991) y por uno de nosotros en el caso de su aplicación a la enseñanza de la Geografía en educación secundaria (SOUTO, 1983). Ya entonces exponíamos que los estereotipos culturales eran un obstáculo para comprender fenómenos como las migraciones, espacios como los urbanos y la misma concepción de la disciplina de la Geografía.

Esta separación entre teoría y práctica pretendimos superarla a través del concepto de praxis didáctica. Así lo indicábamos en el subtítulo de cada libro del profesorado de la colección de Gea-Clío, buscando integrar la reflexión teórica en las propuestas pragmáticas de tareas educativas (BOIRA; 
REQUES; SOUTO, 1994). Esta preocupación la hemos visto reflejada en diferentes cursos de formación docente, donde apreciamos otra paradoja educativa: la Geografía se asocia sobre todo a mapas, territorio y espacio. Sin embargo, hemos comprobado que no se utiliza el lenguaje cartográfico como medio fundamental para interpretar y sistematizar la información que seleccionamos de los hechos y fenómenos sociales y espaciales.

Tabla 2

Ideas/Palabras Asociadas a Geografía

\begin{tabular}{|c|c|c|}
\hline $\begin{array}{l}\text { Personas y fecha del } \\
\text { curso }\end{array}$ & $\begin{array}{c}\text { Palabras asociadas a } \\
\text { Geografía }\end{array}$ & $\begin{array}{c}\text { Comentarios surgidos en el } \\
\text { debate }\end{array}$ \\
\hline $\begin{array}{l}30 \text { Alumnos del Máster de } \\
\text { Secundaria UV, 22/10/2015 }\end{array}$ & $\begin{array}{l}\text { Mapas (5), Paisaje (3), } \\
\text { Ambiente (3), Mundo (2) }\end{array}$ & $\begin{array}{l}\text { Los resultados corresponden a } 5 \\
\text { grupos de } 4 \text { personas, después de } \\
\text { comparar los resultados individuales }\end{array}$ \\
\hline $\begin{array}{l}15 \text { Profesores. Olimpíadas de } \\
\text { Geografía UV, } 4 / 3 / 2016 . \\
\text { Profesores en activo de } \\
\text { Secundaria }\end{array}$ & $\begin{array}{l}\text { Te r r i to r i o ( } 8 \text { ), } \\
\text { Interdisciplinariedad (5), } \\
\text { Mapas (4), Sociedad (3), } \\
\text { Localización (3) }\end{array}$ & $\begin{array}{l}\text { La materia es compleja para las per- } \\
\text { sonas que proceden de formación } \\
\text { inicial de Historia }\end{array}$ \\
\hline $\begin{array}{l}3^{\circ} \text { Grado, } 35 \text { personas, } \\
29 / 10 / 2015 \text { (Magisterio } \\
\text { Universidad Valencia) }\end{array}$ & $\begin{array}{l}\text { Mapas (24), Países (20), } \\
\text { Montañas (13), Ríos (1 1), } \\
\text { Población (9), Clima (6). }\end{array}$ & $\begin{array}{l}\text { Trataban de recordar su imagen de } \\
\text { los estudios de Secundaria }\end{array}$ \\
\hline $\begin{array}{l}\text { Perú. } 88 \text { profesores. } \\
8 / 12 / 2016 \text {. }\end{array}$ & $\begin{array}{l}\text { Espacio (56), Mapa (29), ter- } \\
\text { ritorio (20), Localización (19). }\end{array}$ & $\begin{array}{l}\text { Era u } \\
\text { con € } \\
\text { gené }\end{array}$ \\
\hline $\begin{array}{l}\text { Máster de de Formación de } \\
\text { Profesorado de Secundaria } \\
25 / 10 / 2016,40 \text { alumnos } \\
\text { que se forman para ser do- } \\
\text { centes de Secundaria en la } \\
\text { Universidad de Valencia }\end{array}$ & $\begin{array}{l}\text { Mapas-cartografía (16) } \\
\text { Clima-meteorología (1 1), } \\
\text { Relieve (10), Gráficas (10) } \\
\text { Población (8), Espacio (6), } \\
\text { Práctica (6), Memorizar, } \\
\text { Global, Medio ambiente, } \\
\text { Frontera, Entorno (5). }\end{array}$ & $\begin{array}{l}\text { En el orden jerárquico de las pala- } \\
\text { bras predominan las asociadas a } \\
\text { la geografía física, en especial con } \\
\text { relieve y clima, donde se añade } \\
\text { la expresión "cambio climático", } \\
\text { bajo la influencia de los medios de } \\
\text { comunicación }\end{array}$ \\
\hline
\end{tabular}

Fuente: Elaboración propia sobre datos aportados en seminarios de formación docente

El trabajo realizado con estas muestras aleatorias nos ha permitido analizar críticamente las técnicas y métodos utilizados. Así hemos sido conscientes de la necesidad de delimitar muy bien los sujetos en sus colectivos: por una parte eran profesores en formación continua (grupo de Perú) que deseaban participar en esta actividad, que les resultaba gratificante $y$, por otra, futuros docentes que veían la tarea como una más de su formación. Al analizar 
sus respuestas hemos visto que hay algunas palabras (evocaciones) que se repetían, en especial "mapas" o "cartografía". Ellos nos condujo a un nuevo método de trabajo: plantear qué entendían por mapa y cómo representaban el mapa del mundo (proyección Mercator, Peters u otra), para mostrar que el mapa era una representación política, no neutra, de la realidad, lo que desconocían en casi la totalidad de los sujetos, pues no se habían planteado el problema de la fidelidad de la representación cartográfica con las superficies del territorio. Es decir, las representaciones del mundo nos permitían identificar dos elementos complementarios: por una parte, la concepción de que los mapas "son la realidad" y por otra que "la concepción eurocéntrica del planeta" es la visión verdadera del mismo. Entendemos que ello sí constituye una representación social, una totalidad significante, de acuerdo con el modelo de Serge Moscovici, pues está asentada en los hábitos de docentes y discentes, como hemos comprobado en nuestras investigaciones en un lado y otro del Atlántico. Incluso entre quienes se muestran críticos con el colonialismo cultural de los manuales escolares procedentes de Europa no son capaces de observar este hecho en la presentación cartográfica del mundo.

La representación de la Geografía como mapas, territorio y espacio, 20 así como la del profesor, asociado a las palabras de dinamismo y motivación, nos ha llevado a buscar una lógica teórica a la interpretación de estas palabras y por eso hemos acudido a las representaciones sociales como teoría que relaciona el contexto social con los argumentos personales. Es decir, buscamos entender los motivos por los cuales un docente de Geografía entiende que su objetivo es guiar el aprendizaje de los problemas sociales y espaciales y no considera necesario conocer las escuelas de Geografía, que presentan diferentes maneras de concebir estas situaciones, en especial buscando una complementariedad entre el contexto social y las percepciones individuales. lgualmente deseamos explicar los motivos por los cuales la Geografía se asocia a espacio, territorio y mapas y no se utilizan estos conceptos y técnicas para definir los problemas de los lugares donde viven los alumnos o que se perciben a través de los medios de comunicación.

En la búsqueda de preguntas para seguir cuestionando la realidad percibida por el alumnado nos encontramos en la siguiente situación. Disponemos de un conjunto de datos (resultados de encuestas, de grupos de debate) que nos revelan una manifestación de la geografía escolar asociada a las rutinas académicas, pero también a la influencia del contexto social. Las resistencias 
al cambio de los sujetos implicados, como son las familias de los alumnos (FERNÁNDEZ; GUVERICH; SOUTO; BACHMANN; AJÓN; QUINTERO, 2010), de los propios docentes (MÜLLER, 1993) o de la institución universitaria (RAMIRO, 1998) nos pone de relieve que las ideas se construyen en un determinado contexto social. Por eso necesitamos conocer cómo se construyen las representaciones sociales que determinan nuestro comportamiento particular. $Y$ eso es lo que exponemos brevemente en el siguiente punto.

\section{Las representaciones sociales de la geografía como obstáculo para innovar}

El concepto de representaciones sociales cuenta con una tradición filosófica e investigadora que se originó en el siglo XIX, fundamentalmente desde la psicología. Desde la didáctica de las ciencias sociales, y muy especialmente en Geografía, nos interesa conocer la organización y el significado del sentido común para poder responder a una serie de cuestiones sobre el origen y la naturaleza del saber que se origina en las interacciones cotidianas, así como cuál es el contenido del que se nutre (CASTORINA; HORN, 2008).

Sin duda, el funcionamiento social está determinado por lo que podemos conocer cómo la psicología de masas (MOSCOVICl, 201 1). Algo que se ha estudiado desde la sociología y psicología y que a nosotros nos interesaba en cuanto que dichas teorías nos permitían entender las resistencias a la innovación educativa. Por eso nos interesaron las afirmaciones de Jodelet (1991, p. 43) asociando la construcción social del conocimiento con la presentación de una realidad social, que se presenta como "natural" y estática, que para los docentes es "[...] el temario que hay que impartir en las aulas". Son realidades asumidas desde una condición pre-reflexiva y, por tanto, se derivan en comportamientos que no se razonan, se asumen. En esta línea de reflexión teórica nos ha interesado conocer cómo se formulan los contenidos del posible núcleo central de dicha representación social, o sea aquellas emociones y razonamientos que se mantienen estables más allá de las coyunturas históricas. Unas representaciones que se pueden comparar epistémicamente a un proceso de elaboración cognitivo y que se manifiesta en las expresiones escolares (MOLINER; ABRIC, 2015). 
La representación es un corpus organizado de conocimientos y una de las actividades psíquicas gracias a las cuales los hombres hacen inteligible la realidad física y social, se integran en un grupo o en una relación cotidiana de intercambios, liberan los poderes de su imaginación (MOSCOVICl, 1979). Esta teoría nos permitía entender las concepciones espontáneas del alumnado (el sentido común, el conocimiento vulgar), que veníamos trabajando desde los años noventa del siglo pasado y que hemos sintetizado en la figura 1. La aportación que ahora conocemos es que las representaciones son algo más, un conjunto de ideas que se elaboran en un determinado contexto y por eso es preciso definir muy bien dicho ámbito de elaboración de las representaciones.

Figura 1

\section{Síntesis del Concepto de Representaciones Sociales}

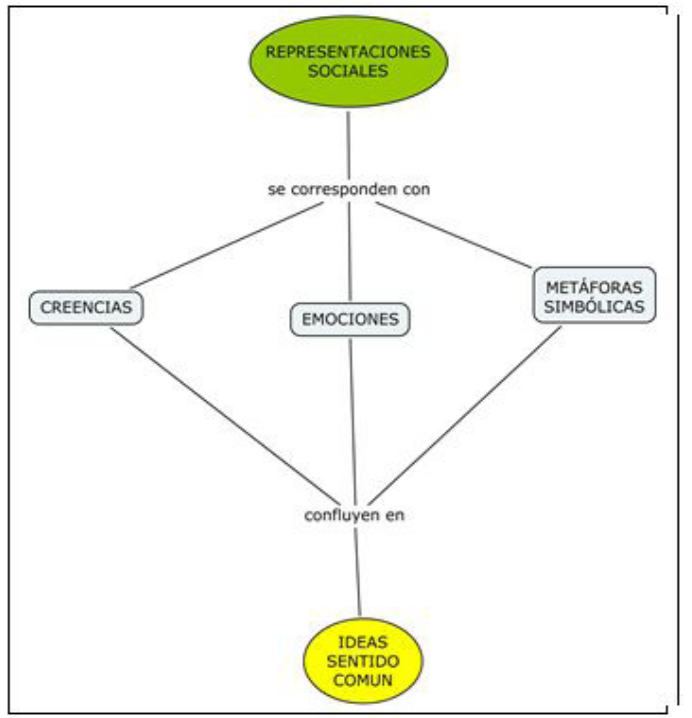

Fuente: Elaboración propia

Las representaciones sociales tienen una doble función. Por un lado, como modo de conocimiento o actividad de reproducción de las características de un objeto (reconstrucción mental); por otro lado, como una forma de pensamiento social que estructura la comunicación y las conductas de los miembros de un grupo. Finalmente, las representaciones sociales permiten que los sujetos construyan un pequeño modelo explicativo y evaluativo del entorno, a 
partir de un discurso, que le permite otorgar un sentido y le guía para funcionar en la vida social, contribuyendo en la resolución de problemas, conflictos y nuevas incertidumbres.

La comprensión de sus reglas de articulación permite también conocer la organización interna de su contenido o núcleo central de la representación (ABRIC, 2001) en el que interviene la dualidad del contexto. Por un lado, el contexto discursivo o la naturaleza de las condiciones en las que se producen los discursos, en las que intervienen las relaciones entre los sujetos que se suceden en el tiempo de interacción; por ejemplo las relaciones educativas sobre la innovación escolar: un conocimiento disciplinar y pedagógico para ejercer la función docente. Por otro lado, el contexto social en el que se activan o se desactivan las representaciones sociales y se generan contradicciones aparentes derivadas de una dualidad entre la lógica cognitiva (racional y coherente) y la lógica social (irracional y e incoherente).

\section{El contexto social de la producción de la geografía escolar}

Desde la perspectiva del análisis de la docencia en la Geografía escolar nos interesa la aportación de las representaciones sociales como síntesis de las influencias sociales e individuales en la forma de trabajar el profesorado, que como sabemos por otros estudios desde la enseñanza de la Historia es un elemento esencial para el agrado o desinterés del alumnado por la materiab.

Las aportaciones de Domingos Sobrinho (2000; 2010) y Saraiva (2007) nos acercan el análisis psicológico de Moscovici con el sociológico de Bourdieu, en la búsqueda de la explicación del hábitus docente en la forma de explicar la Geografía escolar. En primer lugar influyen las características de origen social y familiar del propio docente, lo que determina su concepción del sistema escolar, luego influye decisivamente su formación inicial y continua, con las lecturas que pueda realizar, los seminarios de trabajo que pueda fomentar y los debates con otros colegas. Todos estos factores van modelando la figura docente, así como su concepción de la materia, en este caso Geografía.

Por otra parte, las representaciones sociales nos permiten una lectura epistémica de los modelos pedagógicos y psicológicos, como es el caso del constructivismo. Se tiene en consideración las capacidades del individuo según su crecimiento biológico (las fases de equilibrio/desequilibrio de Piaget) 
y además las interacciones con el medio cultural, donde existe una zona de desarrollo próximo que estimula el uso neuronal para construir las relaciones sinápticas. En este sentido la repercusión en la enseñanza de la Geografía es importante, pues nos ofrece un camino para la gradación en la secuencia de actividades. Y otra vez, la escuela de la Percepción y el Comportamiento es relevante para poder graduar los aprendizajes estructurales del medio (localización, situación, orientación) y las valoraciones del espacio vivido, donde la topofilia y topofobia son conceptos explicativos.

Nuestra conjetura indica que las continuas reformas administrativas suponen un obstáculo para la innovación al considerar el profesorado que en las instancias políticas partidistas se determinan los contenidos escolares. Es decir, las representaciones sociales del docente actúan como obstáculo para innovar, pues se entiende que ellos/ellas no tienen capacidad ni legitimidad para conformar unos determinados contenidos que se encuentran formulados en el currículo oficial.

En segundo lugar, las representaciones y las percepciones de la vida cotidiana del alumnado no se han considerado de forma genérica en la elaboración de actividades escolares. Ellos entienden que la enseñanza escolar de 24 la Geografía no es útil para resolver problemas de su vida cotidiana.

Por último en el ámbito de las representaciones sociales encontramos un tercer tipo de obstáculos. Nos referimos a la opinión construida con "el sentido común" de las familias, alumnos y ciudadanos en general, que entienden la Geografía escolar como un conocimiento cultural que sirve para conocer curiosidades del mundo. En este sentido, como se argumentará, supone un obstáculo a los proyectos de innovación.

El viejo debate entre el papel de los políticos y los profesionales de la Geografía académica, bien sintetizado por P. Bailey (1986), que trataba de delimitar los espacios de control de cada uno de estas instituciones en la formulación de propuestas educativas. Sin embargo, el conflicto y los obstáculos consecuentes no se derivan de esta polémica, sino de la percepción y representación social que posee el profesorado sobre su papel en la innovación y transformación de la enseñanza escolar de la Geografía. Y en este sentido, en el siglo XXI, la presión de los medios de comunicación es un elemento crucial para definir las concepciones vulgares del profesorado, que tiene de este modo un sentido político. 
Los cambios que se han registrado en el currículo de Geografía, al menos en los países europeos e iberoamericanos, obedecen a las presiones de las instituciones académicas y gubernamentales por asentar un tipo de conocimiento que se entienda coherente con la cultura básica. Se naturaliza una determinada manera de ver la organización del contenido geográfico (en este caso el modelo regional) y se impone al sistema escolar a través de los temarios de contenidos, pues el currículo queda sintetizado en un listado de hechos y conceptos a estudiar.

Disponemos de ejemplos empíricos que nos muestran que la intervención del profesorado en la organización de su formación profesional y en la confección de proyectos de innovación de materiales curriculares fue censurada desde el poder? ${ }^{7}$. Por otra parte, se disponían normativas que determinaban la secuencia de contenidos de la Educación Secundaria, que se realizaba para facilitar la homogeneización de las secuencias disciplinares y dificultar la interpretación desde los grupos de innovación ${ }^{8}$, que no provocó más que escasas reacciones por parte del profesorado, lo que mostraba que las rutinas del sistema escolar eran percibidas como "lógicas y de sentido común" por parte del conjunto de los docentes. $O$ sea, la naturalización del sistema canónico de conocimiento escolar, que se aceptaba en las aulas como lógico e irrefutable.

Por esta misma razón la mayoría de las editoriales y del profesorado siguieron programando sobre unos temas académicos y una metodología clásica. En el bachillerato (ensino médio), la vuelta al paradigma regional y el carácter minucioso de los contenidos conceptuales orientaron la cultura escolar que, además, estaba condicionada por las Pruebas de Acceso a la Universidad, pues orientaban el desarrollo del programa de las asignaturas en segundo curso.

Por eso hemos señalado que era preciso reformar la enseñanza de la Geografía desde los propios presupuestos que se proyectan desde la práctica de la enseñanza básica y que a la universidad corresponde apoyar con investigaciones la búsqueda de alternativas a la situación tradicional (SOUTO, 2013). Este camino está en la línea de los cambios promovidos con notable éxito en otros países para mudar la Geografía escolar, donde es posible encontrar algunas enseñanzas de los errores que se han conocido. En este sentido encontramos ejemplos similares en Alemania, Reino Unido y Argentina. Por una parte, existen interferencias de las autoridades políticas y académicas $y$, por otra, las resistencias de las opiniones y percepciones de las rutinas del profesorado y 
la opinión del sentido común de las familias del alumnado (SOUTO; GARCÍA MONTEAGUDO, 2016).

La conclusión que se puede obtener es la necesidad de abordar los cambios del sistema escolar desde un proyecto a largo plazo que contemple debates entre el profesorado y una campaña de difusión de los nuevos avances en el conocimiento social desde la investigación universitaria. La simple traslación de los avances científicos a las aulas de la enseñanza básica ha resultado insuficiente para promover un cambio de hábitos y contenidos. Un debate que en España también hemos conocido con la denominación de la trasposición didáctica (RODRÍGUEZ LESTEGÁS, 2007).

\section{Los sujetos y la representación geográfica del mundo}

La innovación educativa responde a los intereses profesionales de los docentes que pretenden mejorar el aprendizaje del alumnado. Por ello es importante conocer las representaciones sociales de los alumnos y de sus familias acerca de la propia materia, en este caso, de la Geografía. Con el conocimiento de estas concepciones espontáneas (sentido común), los docentes pueden desarrollar la investigación, dotándose de herramientas y resultados que les permiten avanzar en el camino que se han marcado en su trabajo cotidiano. Con ello defendemos una mayor participación social en la definición de los contenidos que se establecen en las agendas curriculares, sin que esto signifique que la dinámica de las disciplinas deba adaptarse por completo a las demandas sociales. Como ya hemos señalado, las muestras que utilizamos son aleatorias y por eso hemos de precisar el sentido de su selección; no obstante entendemos que muestran adecuadamente las tendencias los cambios percibidos.

Desde el curso académico 2014/2015 hemos realizado más de 200 encuestas $^{9}$ a tres grupos diferentes de personas por su perfil de edad (menores de 30 años, entre 31 a 50 años y mayores de 50 años) para conocer su representación social de la geografía (Tabla 3). Son personas amigas, familiares, compañeros/as de los alumnos del Máster de Formación del Profesorado de Secundaria de la Universidad de Valencia, que se elegían aleatoriamente por pertenecer a los diferentes grupos de edad definidos en clase. El recuerdo de las clases de geografía se asocia al uso de recursos y técnicas, y a las 
explicaciones de los docentes, que son más reconocibles en los grupos más jóvenes.

El estudio comparativo de estas encuestas abiertas nos ha permitido conocer que existe una cierta estabilidad en la concepción de la geografía escolar que recuerdan las personas de diferentes generaciones. En primer lugar destaca el recuerdo de un método memorístico, de tal manera que a veces es lo único que recuerdan, tal como afirmaban en líneas precedentes los mismos alumnos del Máster. Una memorización que se asocia a nombres de lugares, fenómenos o accidentes geográficos.

Ello se podría considerar como una representación social del saber geográfico escolar, como también se ha mostrado en las investigaciones citadas en el caso de Argentina y Alemania. Es decir, las familias como selección de un conjunto social superior tienen esa idea de la geografía escolar, donde la buena memoria del alumno es una característica esencial.

Pero, como mostramos en la tabla 3 en las tres generaciones se producen algunos cambios a lo largo del tiempo. En este aspecto es bien significativa la irrupción de las nuevas tecnologías de la información (TIC) como parte sustancial de los cambios técnicos y metodológicos, aun cuando no se sepa argumentar cuál es la diferencia entre ambos conceptos. Igualmente se percibe un cambio en la finalidad de la materia, pues en las edades más jóvenes es vista como una aportación a la cultura general, mientras que a partir de 30 años se relaciona con la comprensión del mundo. Sin duda, la percepción de una sociedad saturada de información influye en estas concepciones.

\section{Tabla 3}

\section{Percepción Social de la Geografía}

\begin{tabular}{|c|c|c|c|}
\hline & Menores 30 años & 31 a 50 años & Mayores 51 años \\
\hline $\begin{array}{l}\text { 1.-Recuerdo de } \\
\text { las clases de } \\
\text { geografía }\end{array}$ & $\begin{array}{l}\text { Profesores amenos y uso de } \\
\text { técnicas de representación } \\
\text { "El profesor fue excelente. } \\
\text { Contenidos y materiales } \\
\text { adecuados, tanto el manu- } \\
\text { al como las transparencias, } \\
\text { láminas y mapas" }\end{array}$ & $\begin{array}{l}\text { Profesores pacientes y } \\
\text { uso del mapa. } \\
\text { "Haber estudiado las ca- } \\
\text { pitales y los países de los } \\
\text { diferentes continentes" }\end{array}$ & $\begin{array}{l}\text { Recuerdo negativo del } \\
\text { profesor } \\
\text { "te golpeaba con la } \\
\text { vara si errabas en la } \\
\text { respuesta" }\end{array}$ \\
\hline
\end{tabular}




\section{Tabla 3}

\section{Percepción Social de la Geografía (continuação)}

\begin{tabular}{|l|l|l|l|}
\hline $\begin{array}{l}\text { 2.-Función de la } \\
\text { geografía }\end{array}$ & $\begin{array}{l}\text { Cultura general } \\
\text { "Sobre todo la demografía y } \\
\text { geografía política" }\end{array}$ & $\begin{array}{l}\text { Comprender el mundo en } \\
\text { que vivimos } \\
\text { "nos ayuda a entender el } \\
\text { por qué de muchas cosas } \\
\text { del mundo" }\end{array}$ & $\begin{array}{l}\text { Comprender el mundo } \\
\text { en que vivimos } \\
\text { "saber donde están los } \\
\text { lugares a los que nunca } \\
\text { se ha ido" }\end{array}$ \\
\hline $\begin{array}{l}\text { 3.-Elementos ne- } \\
\text { cesarios para ser } \\
\text { buen profesor de } \\
\text { geografía }\end{array}$ & $\begin{array}{l}\text { Técnicas de estudio } \\
\text { (memorización) } \\
\text { "Tener mucha memoria y re- } \\
\text { lacionar los conocimientos } \\
\text { con otras áreas como histo- } \\
\text { ria, arte, política..." }\end{array}$ & $\begin{array}{l}\text { Interés por materia } \\
\text { "Estar motivado por la la } \\
\text { disciplina y los conte- } \\
\text { nidos que nos puede } \\
\text { aportar" }\end{array}$ & $\begin{array}{l}\text { Capacidad } \\
\text { memorización } \\
\text { "Tener memoria para re- } \\
\text { tener nombres" }\end{array}$ \\
\hline $\begin{array}{l}\text { 4.-Percepción so- } \\
\text { bre el cambio en } \\
\text { la enseñanza de } \\
\text { la geografía }\end{array}$ & $\begin{array}{l}\text { Nuevos temarios. Cambios } \\
\text { fronteras y TICs. }\end{array}$ & $\begin{array}{l}65,4 \% \text { (sí) } \\
\text { TICs y preparación } \\
\text { docente }\end{array}$ & $\begin{array}{l}76 \% \text { (sí) } \\
\text { Nuevos recursos y am- } \\
\text { pliación del temario } \\
\text { lescala local) }\end{array}$ \\
\hline
\end{tabular}

Fuente: Elaboración propia sobre encuestas realizadas a sujetos de los tres grupos de edad entre 2014 y 2016

28 Los estudios de campo realizados con el alumnado de dieciséis años de edad ( $4^{\circ}$ de Educación Secundaria en España) nos ponen de relieve que existen diferencias notables en función de las relaciones entre el espacio vivido, concebido y percibido $^{10}$. Por un lado, la pertenencia al espacio rural acerca al alumnado al conocimiento de los problemas sociales que ocurren en su espacio vivido, que explican a partir de las experiencias de sus familiares y amigos que tienen un contacto directo con los pueblos y aldeas. Como ejemplo de esto, los estudiantes del Instituto de Enseñanza Media de Requena ${ }^{1}$, se representan un espacio rural complejo en el que al espacio vivido le superponen una amalgama de emociones (apego por la vida en el campo, sentimiento familiar, mantenimiento de tradiciones populares...) que resultan de la práctica espacial (percepción como espacio social) que han experimentado desde su infancia. Una idea escolar, que como en los casos anteriores está contaminada por una representación social, en este caso bajo el paraguas de las teorías de la modernización (ENTRENA, 1998).

En síntesis, con estos resultados se pone de manifiesto que la misma complejidad de las representaciones sociales, sugiere el conocimiento que los agentes educativos (profesores, directivos y personal no docente) tienen sobre 
el sistema educativo y sobre las materias en general. Es una tarea que se tiene que pensar y reflexionar para conseguir resultados a largo plazo, ya que conocer las representaciones sociales implica aspectos psicológicos, personales y profesionales de todos los miembros de la comunidad educativa. Por otra parte, en relación con la imagen de la geografía escolar aparece una representación nuclear que confirma la presencia de esta materia asociada a mapas $y$, en el siglo XXI, a las nuevas tecnologías de la representación del territorio. En este sentido aparece el peligro de confundir la metodología didáctica con el uso de estas técnicas e instrumentos cartográficos, lo que nos retrotrae a los viejos debates de los años setenta con la incorporación de los medios audiovisuales en la educación básica.

\section{¿Qué se hace en geografía académica como referente de la geográfia escolar?}

De la situación que hemos diagnosticado cabe esperar una respuesta por parte de las personas, de forma individual y colectiva, que actúan en el medio escolar. Para poder valorar la búsqueda de soluciones a la problemática indicada hemos seleccionado dos casos complementarios. Por una parte, la producción que se ha generado en el seno de las asociaciones geográficas profesionales y universitarias. Por otra parte, las propuestas de innovación que han surgido desde la práctica de la enseñanza escolar de la Geografía con alumnos de edades de enseñanza obligatoria.

El estudio realizado sobre la producción bibliográfica del Boletín de la Asociación de Geógrafos Españoles (SEBASTIÀ; TONDA, 2015) nos permite comprobar la escasa dedicación que se le ha prestado a este ámbito de conocimiento, pese a que como se ha señalado desde las propias investigaciones académicas la institucionalización de la Geografía se deriva de su presencia en la enseñanza básica.

Además el estudio realizado respecto a la preocupación que procede de la Asociación Universitaria de Profesores de Didáctica de las ciencias sociales nos muestra que la enseñanza de la Geografía es subsidiaria de la enseñanza de la Historia y que, además, el grueso de las aportaciones radican más en el análisis del currículo oficial que en investigaciones sobre la práctica de aula (TONDA; SEBASTIÀ, 2012). 
En el estudio comparativo de las principales revistas geográficas (SEBASTIÀ; TONDA, 2014) nos indican que existe un predominio de la enseñanza secundaria sobre el resto de los niveles, en gran medida por las características profesionales del profesorado asociado de las universidades españolas y por la escasa tradición de investigar en los restantes niveles. Además observamos en la misma tabla número 6 , como la mayoría de los artículos inciden en asuntos curriculares y no en la metodología del aula ni en el análisis del aprendizaje del alumnado; una situación algo diferente a la que se registra en otras revistas como Scripta Nova, donde se visualiza una mayor atención a los asuntos metodológicos de carácter internivelar.

\section{Tabla 4}

Características de la Producción Editorial de la Enseñanza de la Geografía

\begin{tabular}{|c|c|c|c|c|}
\hline & Boletín AGE & Scripta Nova & $\begin{array}{l}\text { Didáctica } \\
\text { Geográfica }\end{array}$ & $\begin{array}{l}\text { Rev. Enseñanza } \\
\text { CC.SS }\end{array}$ \\
\hline $\begin{array}{l}\mathrm{N} \text { i v e l es } \\
\text { educativos }\end{array}$ & . & $\begin{array}{l}\text { 30\% Secundaria; } \\
\text { Primaria (10\%); } \\
\text { Universidad (7\%); } \\
\text { Internivel: } 50 \%\end{array}$ & $\begin{array}{l}49,2 \% \text { Secundaria } \\
21,3 \% \text { Primaria y } \\
\text { Universidad } \\
4,9 \% \text { Infantil }\end{array}$ & $\begin{array}{l}\text { 41,9\% Secundaria } \\
\text { 18,5\% Primaria } \\
\text { 14\% Universidad } \\
\text { 3,7\% Infantil }\end{array}$ \\
\hline $\begin{array}{l}\text { Temáticas } \\
\text { abordadas }\end{array}$ & \begin{tabular}{|l|} 
Currículo 86\% \\
Recursos 10\% \\
Epistemología 4\%
\end{tabular} & $\begin{array}{l}\text { 34\% Metodología } \\
\text { 25,5\% Contenidos } \\
\text { 23,4\% Recursos }\end{array}$ & & $\begin{array}{l}\text { Currícul o } \\
\text { Con te n i dos o } \\
\text { Formación docente }\end{array}$ \\
\hline
\end{tabular}

Fuente: Elaboración propia sobre datos de Sebastià y Tonda (2014).

Además señalan que en los congresos del Grupo de Didáctica de la Geografía celebrados desde 2000 a 2010 y siguiendo el mismo orden, los resultados fueron los siguientes: métodos (33\%), contenidos $(25 \%)$, recursos $(20 \%)$, currículo (12\%), formación docente (8\%) y epistemología y dificultades de aprendizaje $(1 \%)$, respectivamente.

En los congresos ibéricos de enseñanza de la Geografía en el período 2001-2011 los contenidos investigados se distribuyeron del siguiente modo: recursos (38\%), métodos (19\%), contenidos (18\%) evaluación (13\%), currículo (8\%) y epistemología 4\%. De la comparación de estas publicaciones se deduce la reiteración de algunas categorías comunes a todas ellas: currículo, recursos y epistemología. La categoría de recursos didácticos se puede definir como 
un centro de interés común en todas las publicaciones científicas (SEBASTIÀ; TONDA, 2014).

Como hemos podido apreciar en estas investigaciones bibliográficas, el análisis de la Geografía escolar está muy anclado en el estudio de currículo, métodos y recursos. Existe un menor análisis de las representaciones de la práctica del aula, de las percepciones docentes y discentes y de los sueños de los grupos de innovación. Entendemos que dicha orientación cualitativa es muy relevante para cuestionar las rutinas escolares y buscar vías de innovación. Para este desafío es necesario cimentar las bases teóricas sobre las que levantar los andamios empíricos del edificio alternativo. $Y$ en esta construcción para la autonomía crítica ciudadana hemos querido contribuir desde esta comunicación.

Una aportación que somos conscientes que es limitada, pero que se acompaña de un trabajo más constante a través de proyectos curriculares, que proceden del trabajo de colectivos de docentes de enseñanza secundaria. En este caso resulta obvio que existe un claro descenso en las actividades realizadas desde estos grupos y proyectos. Si en los años ochenta del siglo XX podíamos contar con las aportaciones de grupos ya consolidados (como Germanías-Garbí o Cronos) y otros que aparecían en estos años (Ínsula Barataria, Ires, Gea-Clío, Pagadi), en los primeros decenios del siglo XXI dichos grupos han desaparecido, a excepción de Ires y Gea-Clío. Aparecen, como contrapartida, diversos blogs y páginas webs de profesores y centros escolares que difunden sus experiencias de aula, muchas veces sin una reflexión sobre las posibilidades de generalización a otros centros escolares.

En los grupos pedagógicos se buscaba la innovación a través de la reflexión teórica con la práctica escolar, la investigación de estudios de casos con propuestas de mejora en las aulas, la evaluación del aprendizaje escolar con modelos de formación docente. Un programa de investigación que se ha buscado compartir a través de instrumentos como el Geoforo lberoamericano - Fedicaria. La teoría de las representaciones sociales nos ha permitido indagar en las concepciones vulgares de los docentes y alumnos que se generan en un marco social. Es decir, dichas concepciones "entran en las aulas escolares" desde el exterior. Con este artículo hemos querido contribuir a conocer algunas técnicas de trabajo que nos permiten explicar los factores sociales que condicionan las tareas escolares y obstaculizan en más de una ocasión la innovación didáctica. 


\section{Notas}

1 El presente trabajo es resultado parcial de las investigaciones realizadas en un proyecto de investigación, con título "Las marginaciones personales y la utilidad social del saber escolar" y referencia GVAICO2016-092, en el marco de la convocatoria de la Conselleria d'Educació, Cultura i Esports para Ayudas para Grupos de Investigación Consolidables (Orden 6/2015, de 9 de septiembre). Igualmente se inserta dentro del proyecto "Competencias sociales para una ciudadanía democrática: análisis, desarrollo y evaluación". COMDEMO (Red 14) dentro del marco del Plan Nacional de I+D+i del Gobierno de España y de los Fondos FEDER de la UE (EDU2015-6562 1-C3-1-R).

2 Para la REDLADGEO se puede consultar la página web de Geopaideia: (http://www.geopaideia.com/?page_id=6) y para el Geoforo: geoforo.blogspot.com.es.

3 En este sentido hemos de señalar la relevancia que adquiere establecer redes profesionales con diversos científicos, como ha sido en nuestro caso con personas procedentes de la neurociencia Uosé Luis Díaz en México) o de la Sociología (Moisés Domingos en Brasil), además de con otros geógrafos (como Rafael Straforini en Brasil) que ha iniciado una fecunda relación con el grupo de Ernesto Laclau en Argentina.

4 El análisis específico de los datos de estas encuestas lo podemos ver en Souto y García (2016).

5 El procesamiento de las palabras más relacionadas con los conceptos sugeridos ha sido realizado con la ayuda del software EVOCATION 2005, siguiendo el trabajo de Domingos Sobrinho (2010).Las palabras asociadas han sido filtradas por el software en una serie de funciones hasta ofrecer un listado ordenado que jerarquiza el núcleo central respecto de los elementos periféricos a partir de la frecuencia y el rango de las palabras como parte del método psico-cognitivo.

6 Sobre estas cuestiones hemos desarrollado una larga investigación en relación con los recuerdos escolares de la Historia de España (MARTíNEZ; PARRA; SOUTO, 2014).

7 Sobre esta cuestión se puede consultar Souto González, Xosé M (1998). La calidad de la enseñanza y la formación del profesorado. El caso de la Comunidad Valenciana, Conceptos de Educación, número 4, páginas 57-69; además también Mesejo González, Casimiro y Souto González, Xosé Manuel. Centros de formación do profesorado. Vigo: Xerais, 1993.

8 Nos referimos al Decreto de enseñanzas mínimas del MEC (BOE de 25 de marzo de 1992); es decir, en el primer año de experimentación de la LOGSE.

9 Estamos hablando de 216 encuestas realizadas en los cursos escolares 2014/15, 2015/16, 2016/17, 2017/18. Los alumnos del Máster de Profesorado de Secundaria de la Universitat de València entrevistaban a personas que tenían los rangos de edad citados.

10 Nos referimos al Trabajo Final de Máster de Diego García, presentado en la Facultat de Magisteri el 8 de julio de 2016, con el título "La representación social del medio rural en la geografía escolar".

11 Requena es un municipio del interior de la provincia de Valencia, pero con suficiente entidad para ser capital comarcal. La población municipal supera escasamente los 20.000 habitantes. 


\section{Referencias}

ABRIC, Jean Claude. A abordagem estrutural das representações sociais. In: MOREIRA, Antônia Silva Paredes; OLIVEIRA, Denise Cristina (Org.). Estudos interdisciplinares de representação social. Goiânia: AB, 2000.

ABRIC, Jean Claude. Metodología de recolección de las representaciones sociales. En: Practiques sociales et Représentations. Traducción al español José Dacosta y Fátima Flores. México: Ediciones Coyoacán, 2001.

BAllEY, Charles Philamore. A geographer's view: contributions of geography to school curriculum. Geography, v. 3, p. 193-205, 1986.

BOIRA, Josep Vicent; REQUES, Pedro. Introducción al Estudio de la Percepción Espacial. Principado de Andorra: Consejería de Educación de los Centros Docentes Españoles, 1991.

BOIRA, Josep Vicent; REQUES, Pedro; SOUTO, Xosé Manuel. Espacio subjetivo y geografía. Orientación teórica y praxis didáctica. Valencia: Nau Llibres, 1994.

CAPEL, Horacio. Percepción del medio y comportamiento geográfico. Revista de Geografía, Barcelona, v. 7, p. 58-150, 1973.

CASTORINA, José Antonio; HORN, Axel. El derecho a la privacidad en los niños, un enfoque constructivista e institucional. Anuario de investigaciones, Buenos Aires, n. 15, p. 197-206, 2008.

DAMASIO, Antonio. Y el cerebro cambió al hombre. Barcelona: Destino, 2010.

DÍAZ, José Luis. La conciencia viviente. México: Fondo de Cultura Económica, 2007.

DOMINGOS SOBRINHO, Moisés. Habitus e representações sociais: questões para o estudo de identidades coletivas. In: MOREIRA, Antônia Silva Paredes; OLIVEIRA, Denize Cristina de (Ed.). Estudos interdisciplinares de representação social. Goiânia: AB Editora, 2000.

DOMINGOS SOBRINHO, Moisés. Representações Sociais como obstáculos Simbólicos à Incorporação do Habitus Científico. Ariús, Campina Grande, v. 16, n. 1/2, p. 31-48, jan./dez. 2010.

ENTRENA, Francisco. Cambios en la construcción social de lo rural: de la autarquía a la globalización. Madrid: Tecnos. 1998.

ESTÉBANEZ, José. La geografía de la percepción del medio y la ordenación del territorio. Paralelo, v. 37, p. 5-22, 1979. 
FERNÁNDEZ, María Victoria; GUVERICH, Raquel; SOUTO, Patricia; BACHMANN, Lía; Ajón, Andrea y QUINTERO, Silvina. La imagen pública de la Geografía, una indagación desde las visiones de profesores y padres de alumnos secundarios. Biblio $3 \mathbf{W}$, Revista Bibliográfica de Geografía y Ciencias Sociales, Barcelona, v. 15, n. 859, 2010 . Disponible en: http://www.ub.edu/geocrit/b3w-859.htm. Acceso: 4 mayo 2016.

GARCÍA MONTEAGUDO, Diego. La representación social del medio rural en la geografía escolar. 2016.161 p. Trabajo Final de Máster inédito. Máster Universitario en Didácticas Específicas) - Facultat de Magisteri. Universitat de València, 2016.

GASPAR, Jorge; MARÍN, Ana. A percepção do espaço. Documentos para o ensino. Finisterra, Lisboa, v. 10, n. 20, p. 317-322, jul./dez. 1975.

JODELET, Denise. La representación social, fenómenos, concepto, teorías. En: MOSCOVICl, Serge (Ed.). Psicología social II, pensamiento y vida social. Barcelona: Grupo Paidós. 1985.

JODELET, Denise. Representações sociais: um domínio em expansão. In: JODELET. Denise (Org.). As representações sociais. Rio de Janeiro: EdUERJ, 2001.

MARTíNEZ, Nicolás; PARRA, David; SOUTO, Xosé Manuel. La representación poliédrica de 34 la memoria escolar. Un proyecto de investigación sobre las clases de Historia de España. En: MARTíNEZ, Nicolás (Coord.). La Historia de España en los recuerdos escolares. Análisis, interpretación y poder de cambio de los testimonios de profesores y alumnos. Valencia: Nau Llibres, 2014.

MESEJO, Casimiro; SOUTO, Xosé Manuel. Centros de formación do profesorado. Vigo: Ediciones Xerais de Galicia, 1993.

MOLINER, Pascal; ABRIC, Jean-Claude. Central core theory. In: SAMMUT, Gordon, ANDREOULI, Eleni; GASKELL, George; VALSINER, Jaan (Ed). The Cambridge handbook of Social Representations. Cambridge University Press, 2015.

MOSCOVICl, Serge. El psicoanálisis, su imagen y su público. Buenos Aires: Huemul S.A., 1979.

MOSCOVICl, Serge. A invenção da sociedade. Sociologia e Psicologia. Petrópolis: Editora Vozes, 2011.

MÜllER, Alois. ¿Qué queda de la Reforma? Terra, n. 5, p. 22-25, 1993. 
RAMIRO, Enric. Institucionalització i difusió de la Geografia Escolar: la Percepció del professorat de la comarca de la Ribera. Tesis Doctoral, Departamento de Geografia, Unversity de Valência, València, 1998.

RODRÍGUEZ LESTEGÁS, Francisco. El problema de la transposición en la enseñanza de la Geografía: ¿̇Y si la transposición fuese el problema? En: ÁVILA RUIZ, Rosa María; LÓPEZ ATXURRA, José Rafael; FERNÁNDEZ DE LA REA, Estibaliz (Ed.). Las competencias profesionales para la enseñanza-aprendizaje de las Ciencias Sociales ante el reto europeo y la globalización. Bilbao: Asociación Universitaria de Profesores de Didáctica de las Ciencias Sociales, 2007.

SARAIVA, Josélia. Habitus docente e representaçao social do ensinar geografia na Educaçao Básica de Teresina-Piauí, Natal. 2007. 193f. Tese (Doutorado em Educação) - Programa Pós-Graduação em Educação, Universidade Federal Río Grande do Norte, Natal, 2007.

SEBASTIÀ, Rafael; TONDA, Emilia María. Líneas de investigación e innovación en la enseñanza de la Geografía a partir de la revista Scripta Nova. Ar@cne. Revista electrónica de recursos en Internet sobre Geografía y Ciencias Sociales, Barcelona, $n^{\circ} 186$, jul. 2014. Disponible en: http://www.ub.edu/geocrit/aracne/aracne-186.htm. Acceso: 3 mayo 2016.

SEBASTIÀ, Rafael; TONDA, Emilia María. Investigación e innovación en la enseñanza de la Geografía a partir del Boletín de la Asociación de Geógrafos españoles: análisis bibliométrico. Boletín de la Asociación de Geógrafos españoles, Sevilla, v. 68, p. 429-448, mayo/ ago. 2015.

SOUTO, Xosé Manuel. Por um ensino crítico: a xeografía da percepción e do comportamento. Terra, Santiago, n. 1, p. 63-76, 1983.

SOUTO, Xosé Manuel. Didáctica de la Geografía, problemas sociales y conocimiento del medio. Barcelona: Ediciones del Serbal, 1998.

SOUTO, Xosé Manuel. ¿Qué escuelas de Geografía para educar en ciudadanía? Didáctica de las ciencias experimentales y sociales, Valencia, n. 24, p. 25-44, 2010.

SOUTO, Xosé Manuel. Investigación e innovación educativa: el caso de la Geografía escolar. Scripta Nova. Revista Electrónica de Geografía y Ciencias Sociales, Barcelona, v. 17, n. 459, dic. 2013 . Disponible en: http://www.ub.es/geocrit/sn/sn-459.htm. Acceso: 3 mayo 2016. 
SOUTO, Xosé Manuel; BARRIO, José María. La enseñanza de la geografía en el Reino Unido. ConCiencia Social, Anuario de Didáctica de Geografía, Historia y otras Ciencias Sociales, Madrid, n. 2, p. 149-162, 1998 (Editorial Akal).

SOUTO GONZÁLEZ, Xosé Manuel; GARCÍA MONTEAGUDO, Diego. La geografía escolar ante el espejo de su representación social. Didáctica Geográfica, Madrid, n. 17, p. 177$201,2016$.

TONDA, Emilia María y SEBASTIÀ, Rafael. Diez años de didáctica de la Geografía a través de los Congresos Nacionales del Grupo de Didáctica de la Geografía (1988-1998). En: MIGUEL, Rafael de; LÁZARO, María Luisa de; MARRÓN, María José (Ed.). La educación geográfica digital. Zaragoza: Grupo de Didáctica de la Asociación de Geógrafos Españoles, 2012.

Prof. Dr. Xosé M. Souto González

Universitat de València

Didáctica de las Ciencias Sociales Departamento de Didáctica de las Ciencias Experimentales y Sociales Grupo de Investigación y de Innovación en Educación Geográfica e Histórica,

SOCIAL(S)

E-mail: Xose.Manuel.Souto@uv.es

Prof. Ms. Diego García Monteagudo

Universitat de València

Didáctica de las Ciencias Sociales

Departamento de Didáctica de las Ciencias Experimentales y Sociales. Grupo de Investigación y de Innovación en Educación Geográfica e Histórica, SOCIAL(S) E-mail: Diego.García-Monteagudo@uv.es

Recebido 3 jun. 2018 Aceito 10 jul. 2018 